\title{
Solid Dispersions of Biologically Active Substances
}

\section{Salavat S. Khalikov}

A.N. Nesmeyanov Institute of Elementoorganic Compounds Russian Academy of Sciences, 119991, 28, Vavilov str., Moscow, Russia

E-mail: khalikov_ss@ineos.ac.ru

\begin{abstract}
Due to the rapid development of nanotechnologies, materials, in particular, solid dispersions (SDs), which are actively introduced into the life of modern man, have been obtained. Special progress in this area is observed in industry and medicine. The use of SDs in agriculture is lagging far behind, despite the growing number of scientific papers on this topic. At the same time, the prospects for the introduction of SDs in the agro-industrial complex are obvious. The review presents the results of research on the development of innovative preparations based on SD to protect plants from diseases and pests of cultivated plants, as well as parasiticides to protect animal health based on modern achievements of nanotechnology. One of these technologies is the methods of mechanochemistry, which improve the properties of poorly soluble biologically active substances by their joint mechanical treatment with water-soluble polymers and auxiliary substances.
\end{abstract}

Key words: Solid Dispersions, Drugs, Anthelminthics, Protectants, Solubility, Mechanochamistry, Biological Active Substances.

\section{Introduction}

Increasing the solubility of poorly water-soluble drugs remains one of the most challenging aspects of drug development. Solubility of active substances (AS) is a step that determines the rate of oral absorption of the drug, which can subsequently affect the absorption of this drug. Due to the problem of solubility, many drugs have low bioavailability and, therefore, increasing the solubility of low-soluble Biologically Active Substances (BAS) becomes a very urgent task. And so SD is one of the most attractive objects for improving the solubility of BAS and they are finely dispersed powders, ideally nanopowders, consisting of a hydrophilic matrix (water-soluble polymers and excipients) and a hydrophobic drug (possibly several AS). Therefore, many of the medicinal substances were announced as a new dosage form of drugs and they are already used in medical practice $[1,2]$ :

-Sporanox ® (itraconazole)

-Intelence ${ }^{\circledR}$ (etravirine)

-Prograf $®$ (tacrolimus)

-Crestor ${ }^{\circledR}$ (rosuvastatin)

-Gris-PEG ${ }^{\circledR}$ (griseofulvin)

-Cesamet ${ }^{\circledR}$ (nabilone) 
It's known that SD was first used in pharmacy to improve the solubility of AS, since they were an effective means of increasing the rate of dissolution and, consequently, the bioavailability of drugs $[3,4]$. Such systems are used:

- to enhance the absorption of the drug.

- to obtain a uniform distribution, a small amount of the drug in the solid state.

- to stabilize unstable drugs and protect against decomposition by processes such as hydrolysis, oxidation, racemization, photo-oxidation, etc.

- for dosing liquid or gaseous compounds.

- for the preparation of a primary dose with a rapid release in a drug form with a delayed release.

- for composing a drug of soluble drugs with delayed release by dispersing the drug in a poorly soluble or insoluble carrier.

- to reduce side effects (a) the binding capacity of drugs, (b) damage to the gastric mucosa by some non-steroidal anti-inflammatory drugs.

- to mask the unpleasant taste and smell of AS.

- for converting liquid compounds into formulations.

\section{Solid dispersions: methods of preparation, properties, application}

It's known that SD is the dispersion of one or more active ingredients in a carrier or matrix in a solid state. There are various methods for obtaining SD, which can be divided into the following [5] :

- varieties of methods using organic solvents (Kneading Method, Solvent melting method, Spray-Drying Method, Gel entrapment technique);

- the methods of Melting /Fusion method;

- the method of co - grinding;

- the method of supercritical fluid.

Usually SD are widely used in medicine [6-10], because these systems can provide many additional advantages:

1. to increase the solubility of poorly soluble drugs, thereby increasing the rate of dissolution, absorption and bioavailability.

2. to improve the drug output of ointments creams and gels.

3. to avoid undesirable incompatibilities.

4. to obtain a uniform distribution of a small amount of the drug in the solid state.

5. to formulate the primary dose of rapid release in a long-release dosage form.

6. to formulate a regime of prolonged release of soluble drugs using poorly soluble or insoluble carriers.

7. to reduce pre-systemic inactivation of drugs such as morphine and progesterone.

The disadvantages of SD drugs [11] are the following factors:

- polymers used in SD can absorb moisture, which can lead to phase separation, crystal growth, or transition from an amorphous to a crystalline state or from a metastable crystalline form to a more stable structure during storage. This can lead to a decrease in solubility and dissolution rate. 
- many water-soluble polymers show excellent results in enhancing the dissolution of drugs, but to achieve high efficiency, a large amount of them is used (from 50 up to $90 \%$ ), which is economically unjustified.

- due to the fact that SD is a high-energy metastable form, phase separation, crystal growth or transformation from an amorphous form to a crystalline one is possible during storage, which reduces solubility and dissolution rate and leads to variable oral bioavailability.

- the technology of obtaining most SD is poorly scaled for production purposes.

- most methods involve the use of solvents that are toxic, flammable and require complete removal from the final product, etc.

Prospects for the use of SD in the field of medicine [11, 12]:

- despite the many advantages of SD, their commercialization is limited due to the complexity and high cost of production processes, reproducibility, complexity of formulations, scaling and stability.

- there are successes in the development of SD for preclinical, clinical and commercial use due to the inclusion of surfactants and self-emulsifying carriers with relatively low melting points in the formulations.

- promising methods for obtaining SD will be methods that exclude the use of solvents.

Thus, the above statement allows us to state that SD is used quite widely in medicine and there are many reviews about this, in addition to research articles [13-16]. However, there are almost no studies on the use of SD in the field of plant protection, except for the work of the author of this review. There are only works on the production of nanopesticides by nanotechnology methods, mainly from inorganic materials in the form of nanoparticles, carbon tubes, etc. [17-20]. It should be noted that modern capabilities of nanotechnology allow us to obtain nanopesticides in the form of nanoparticles, which significantly reduces the impact of agricultural preparations on human health and the environment.

As for the use of SD in the field of animal health protection, namely, the use of SD in the field of Parasitology, there are only a few such works. These include, for example [21], in which a SD of 2 components (ABZ and hydroxypropyl $\beta$-cyclodextrin) of the $1 / 1$ composition contributed to an increase in the bioavailability of ABZ by $40 \%$ compared to its suspension form. Continuing these studies, the authors [22] obtained a SD of the composition albendazole (ABZ) / hydroxypropyl $\beta$-cyclodextrin / L-tartaric acid (molar ratio 1 / 1 / 1), which was absorbed even faster than the known SD of 2 components, which was reflected in the improvement of anthelmintic efficacy against Trichinella spiralis. At the same time, to obtain the target SD of the composition of the ABZ / PVP (1/1) dissolution method was used, namely, the components were dissolved in methanol with stirring for 24 hours and the resulting solution was poured on Teflon sheets. The solvent was removed by evaporation in a partially open desiccator at room temperature for 3 days. The resulting films were carefully ground to a powdery state and dried under vacuum at room temperature for 24 hours and at $40^{\circ} \mathrm{C}$ for 12 hours [23]. This technology is quite time-consuming and includes the processes of dissolution, evaporation of methanol, drying and grinding of polymer films, which is especially time-consuming and with large losses.

The purpose of this review is to show the potential of using biologically active substances to create promising antiparasitic drugs to protect animal health and plant protection products from diseases and pests. 


\section{Solid Dispersions of antiparasitic drugs for animal health}

For the first time, the use of SD for veterinary medicine was reported back in 1995 [24], when the original technology of mechanochemical modification by joint solid-phase treatment of the anthelmintic substance medamine (solubility in water $1 \mathrm{mg} / \mathrm{l}$ ) with apple pectin in the planetary-centrifugal activator AGO-2U was obtained SD named "medapek" with increased water solubility (45 mg / 1). Medapek, while maintaining high activity against nematodes, showed high efficiency and good tolerance in the model of larval echinococcosis of white rats, which is the closest to the corresponding human pathology $[25,26]$. This activity was explained by the formation of a corresponding inclusion complex in water from SD. This conclusion was done based on learning the IR spectroscopy data, dissolution and dialysis methods of SD medapec.

The formation of such inclusion complexes was confirmed on the basis of the IR spectra of SD carbendazim (synonym: medamine), albendazole (ABZ), fenbendazole (FBZ), and triclabendazole (TCB) with PVP and arabinogalactan (AG) [27]. Under similar conditions, the medamine substance and its hydrochloride were subjected to joint mechanical treatment with MCC [28, 29], with plant proanthocyanidines [30], and the corresponding SD were obtained, which had increased solubility in water, better permeability through model semipermeable membranes, and hence increased bioavailability.

Expanding the spectrum of benzimidazole anthelmintics [31], were selected the substances of ABZ, FBZ, TCB and their mixtures, which were modified with such polymers as PVP, polysaccharides (AG, glycyrrhizic acid /GA/ and its derivatives), auxiliary substances (silica gel, others) . The machining of the components was carried out in a metal drum with steel balls in an LE-101 roller mill (manufactured in Hungary) and the corresponding SD were obtained, which were characterized by X-ray and DSC analysis, SEM, IR-spectroscopy, and dissolution in water [32-35] .

Were obtained SD of ABZ and FBZ with polysaccharides - AG, Hydroxyethyl Starch / HES / and polymer PVP. The formation of these SD were confirmed by the above methods [32-39]. The molecular dynamics of the complexes in solution was studied using ${ }^{1} \mathrm{H}$ NMR. The composition of the obtained inclusion complexes and their solubility were monitored by HPLC. Changes in anthelmintic activity have been studied in vitro and in vivo in laboratory animals and sheeps.

SD of ABZ with AG from larch wood Larix sibirica and Larix gmelinii were obtained and investigated physicochemical properties of them in solid state and in aqueous solutions as well as their anthelmintic activity against Trichinella spiralis, Hymenolepis nana, Fasciola hepatica and mixed nematodoses of sheep. The evidence of the inclusion complexes formation was obtained by intrinsic solubility and NMR relaxation technique. It was shown that mechanochemically synthesized SD are more stable as compared to the complex obtained by mixing solutions of the components. SD of ABZ show anthelmintic activity in 10 times reduced doses as compared with free $\mathrm{ABZ}$ and also have a reduced acute toxicity and hepatotoxicity. These results substantiate the possibility of design new drugs on the basis of SD with composion ABZ /AG (1/1) with increased activity and safety of albendazole. Toxicity of the SD was significantly less than ABZ toxicity and it had hepatoprotective effect because of AG in its consist. These results indicate that the SD of ABZ with AG is a potential candidate for therapy [34] .

The SD of fenbendazole (FBZ) with PVP were synthesized using the same mechanochemical technology [35]. Physicochemical studies confirmed the increase in solubility of SD, reducing of particle sizes, amorphization of FBZ substance, and incorporating it with micelles of PVP. The efficacy of SD was studied on the laboratory model of Hymenolepis nana and Trichinella 
spiralis infection of mice and helminthosis of sheeps and was shown that SD of FBZ with PVP was more active than the basic substance of FBZ and its anthelmintic properties were expanded. Thus, the mechanochemically obtained SD of FBZ with PVP polymer can serve as a basis for creating innovative drugs for the treatment of helminthosis in reduced doses [36].

The effect of mechanochemical technology on the anthelmintic efficacy SD of ABZ with licorice extract (EL), which is considered as a means of targeted delivery [37]. The some SD were obtained by mechanochemical technology in the ratio ABZ/ EL (1 / 20) in the form of a light brown powder (SD-1). Similarly, the SD were obtained in the ratio of ABZ / EL (1 / 10) (SD-2), in ratio ABZ / EL ( 1/ 9) (SD-3) and in the ratio of ABZ/ EL (1 / 4) (SD-4). At studying the solubility in water of the substance ABZ and their SDs, as well as suspensions based on these $\mathrm{SD}$, a significant change in this indicator was established. The SD-3 had a 17 times increased solubility after three hours of machining. With an increase in the share of ABZ (from $10 \%$ to $20 \%$ ) in SD-3 and SD-4, the solubility decreased to 13 times. The greatest increase in solubility was observed while producing the drug in the form of a suspension. In a physical mixture, the solubility of ABZ increases only 3 times. In experiments on sheeps naturally infected with Nematodirusis and other species of Strongylates of the digestive tract and Moniesia, it was shown that all SD at a dose of $2.0 \mathrm{mg} / \mathrm{kg}$ of AS showed $90.1-91.7 \%$ efficacy against Nematodirus spp. and 89.5-92.4\% efficacy against other types of gastrointestinal strongylates and 98.6-100\% efficacy against Moniiesa expansa, which is in 4-5 times higher than ABZ activity.

By using above mentioned mechanochemical technology 10 SDs based on the substance of TCB with various water-soluble polymers (HES, PVP, AG, etc.) have been developed without the participation of liquid phases in one stage [38]. These SD are finely dispersed, easily freeflowing, water-soluble powders with a particle size of up to 1-10 microns. In this case, the increase in the solubility of the obtained SDs ranged from 3 to 25 times, depending on the nature of the polymer, and the highest solubility was observed for SD of TCB / AG (1/9), which called Triclafascid. Polysaccharide AG included in the composition of the preparation, isolated from Siberian larch, is widely used in medicine and veterinary medicine [39]. Because of Fascioliasis, localized in the bile ducts, cause their thickening, fatty degeneration and cirrhosis of the liver, and AG, possessing noticeable hepatoprotective and membranotropic properties, provides a high bioavailability of Triclafascid to parasites [40].

Another SD of FBZ with EL and sodium dioctylsulfosuccinate (DSS) is prepared by joint mechanochemical treatment in the ratio $1: 8.9: 0.1$ [41]. The formation of SD was confirmed by observing an increase in the solubility up to 27 times; meanwhile, the solubility of the physical mixture increased only up to 2.6. By studying X-ray and IR-spectra showed that the FBZ particle size decreased, and the FBZ lost crystallinity and acquired an amorphous character; however, no destructive alterations to the FBZ molecule due to mechanical processing were noticed. FBZ is likely to be found on the surface and inside the pores of EL and DSS molecules, which alters the properties and behavior of the active ingredient, and carriers transport it through cellular membranes. Based on obtained results it was confirmed that the enhancement in anthelminthic action is related to the smaller size of FBZ, loss of crystallinity, amorphization, and inclusion of its molecules on the surface and inside the pores of polymers, and as a consequence an increase in solubility and permeability through biological membranes [42].

FBZ was also mechanically modified with $\mathrm{AG}$ and the resulting SD, had an increased (18 times) solubility and in a reduced dose of $3.0 \mathrm{mg} / \mathrm{kg}$ for AS shows $100 \%$ efficiency in Dictyocaulosis, Strongyloidosis and Strongylatosis of the digestive tract and 98,3\% activity in sheeps Trichocephalosis [43], while the recommended dose of the standard drug is $5.0 \mathrm{mg} / \mathrm{kg}$ of AS. But SD of FBZ with PVP and DSS of had the solubility increased up to 24 times, which made it possible to achieve $100 \%$ efficiency in Trichinosis and Hymenolepiasis in white mice 
and gastrointestinal Strongylatosis and Moniesiasis in sheeps at a dose of 2.0 and $3.0 \mathrm{mg} / \mathrm{kg}$, which is lower than the recommended dose of the standard drug [44].

By expanding the spectrum of anthelmintics to other classes of organic compounds (praziquantel / from isoquinolines /; niclosamide / from salicylanilides /), the versatility of the mechanochemical modification technology was shown.

Niclosamide (NS) is widely used to treat cestode infection of animals and for increasing its solubility was used its mechanochemical treatment with PVP and SD in the form of a flowing beige powder was taken [45] . Notable differences were observed with X-ray analysis in the SD of NS and PVP: it was established that a decrease of the intensity of the crystalline phase and disappearance of peaks (reflexes) of NS took place because of disordering of the crystal structure and the formation of the SD in amorphous state. The micrographs showed that the PVP powder was composed of particles of a size of 0.1-0.5 mm while the powder of NS had a broader range of particles of 50-250 micrometers. After mechanochemical processing, destruction of crystalline particles of NS and spherical particles of PVP occurred and aggregates of irregular shape were formed. The study of the solubility of the initial substance of NS in water showed that there was a notable change in this index. The solubility of NS substances with PVP in ratios of $1 / 5 ; 1 / 10$ and $1 / 20$ increased in 11.0, 19.0 and 26.7 times, respectively. The study of anthelmintic efficacy of SD demonstrated a high efficacy of them in different ratios at a dose of $20 \mathrm{mg} / \mathrm{kg} \mathrm{b} / \mathrm{w}$ at oral administration against $H$. nana in mice and $M$. expansa in sheep. Whereas the basic NS was not effective at the same dose [46].

Modification of phenasal (synonym: niclosamide) with $\mathrm{AG}$ and $\mathrm{SiO}_{2}$ made it possible to obtain SD of various compositions with increased solubility in water, which also suggested an increase in anthelmintic activity. [47]. SD of fenasal / AG (1/2) for anoplocephalidosis of horses showed $100 \%$ efficiency at a dose of $20 \mathrm{mg} / \mathrm{kg}$ for AS, while SD of fenasal / PVP (1/2), fenasal / $\mathrm{SiO} 2$ (1/2) and fenasal / AG (1/5) was 75-87\% active [48].

Different samples of SD based on praziquantel (PZQ) with disodium salt of glycyrrhizic acid $\left(\mathrm{Na}_{2} \mathrm{GA}\right)$ were obtained by mechanochemical processing and examined for some physicochemical properties [49]. Based on this study:

- it was found increased solubility, reduction of particle sizes, amorphization of substance, incorporating it with micelles of glycyrrhizic acid and high anthelmintic efficacy in reduced dose.

- the rate of diffusion of PZQ molecules from its SD with $\mathrm{Na}_{2} \mathrm{GA}$ is much higher than that for initial PZQ substance.

- the SD of PZQ was found to be a perspective anthelminthic with enhanced pharmacological activity that needs further research.

The mechanochemical technology for obtaining drugs in form of SD was also effective with mixtures of anthelmintic substances, because the practice of using mixed preparations is an objective necessity in view of the wide range of helminths. So, with the simultaneous invasion of the digestive tract of sheep with Fasciols and Nematodes, the use of SD based on ABZ and TCB with PVP made it possible to achieve $100 \%$ efficiency with a single oral administration at a dose of $4.0 \mathrm{mg} / \mathrm{kg}$ for AS (40 mg / kg for the drug). This dose is 5 times lower than the previously known therapeutic dose of the components. A mixture of ABZ and TCB substances in the same dose showed weak efficiency -22.0 and $24.5 \%$, respectively [50]. This result was obtained due to the SD of ABZ / TCB / PVP (1/1/8) had an increased solubility of the components (ABZ by 14 times; TCB by 8 times). In addition, the advantage of the drug in the form of SD is that the albendazole containing in it does not have an embryotropic effect.

Taking into account the peculiarity of the parasite infestation of animals in the Altai Republic, parasitologists proposed to develop a SD based on three anthelminthics (FBZ, TCB and ivermectin / IVM /). By choosing PVP as a polymer and based on the method of 
mechanochemical technology the following SD were obtained: FBZ / PVP (1/9), TCB / PVP (1/9) , FBZ / IVM / PVP (1/1/9) and TCB / IVM / PVP (1/1/9) [51]. These SDs had increased solubility (14- 29 times). The study of antiparasitic activity in 140 sheep showed high efficiency of SD at doses of FBZ of 3.0 and Iver at $0.2 \mathrm{mg} / \mathrm{kg} \mathrm{b} / \mathrm{w}$ on the following parasites (Strongylata, Moniesia expansa, and Melophagus ovinus), while the therapeutic doses of FBZ and IVM are 5.0 and $1.0 \mathrm{mg} / \mathrm{kg}$. SD based on TCB showed high efficacy against gastrointestinal Strongylata and D. dendriticum and was not effective against Moniesia expansa at doses of TCB 3.0 and IVM $0.2 \mathrm{mg} / \mathrm{kg}$. The parent substances FBZ and TBZ demonstrated a significantly lower efficacy in sheep helminthiasis. The high parasiticidal activity of the studied is compositions explained by increased solubility in water and bioavailability. A threefold decrease in the dosage of FBZ and TCB in drug compositions did not lead to a decrease in their anthelminthic activity [52]. Similarly, the SDs of IVM / AG (1/10) and ABZ / IVM / AG) were obtained, which had increased (12 and 33 times, respectively) solubility. The study of the antiparasitic activity of these SDs in intestinal strongylitis, moniesiasis and melophagosis of sheep (70 pcs) showed that SD in a dose of IVM equal to 0.2 and ABZ - $2.0 \mathrm{mg} / \mathrm{kg}$ (which is 5 times lower than the corresponding therapeutic doses of standard drugs used in practice) was $91.4-100 \%$. At the same time, the starting substances in the same dosages turned out to be less effective [53].

From the above material, it can be seen that the method of mechanochemical solid-phase modification of medicinal substances makes it possible to obtain promising drugs in the form of $\mathrm{SD}$ for the animal health. This method has a number of advantages over the known ones, namely, complete elimination of solvents from the process, one-stage operation, environmental safety, scalability, and technology flexibility.

\section{Solid Dispersions of plant protection products against diseases and pests}

As noted above, there are no examples of the using of SD in the field of plant protection against diseases and pests. There are only works on the effect of nanoparticles of some polymers, in particular, Chitosan, on the biophysical characteristics and growth of Robusta coffee in a greenhouse. At the same time, their influence on the content of chlorophyll, carotenoids, absorption of nutrients and parameters of coffee growth has been shown [54]. It is also known that Fusarium graminearum is one of the most serious diseases of wheat in humid and warm regions, and it significantly reduces yield as well as seed quality. In order to compare the efficacy of combating this disease, Chitosan nanoparticles were used [18], and their significant inhibition of both radial mycelium growth and the number of colonies formed against Fusarium graminearum was shown. An overview of works on delivery systems for Chitosan nanoparticles in agriculture is also presented [17], since Chitosan has proven to be a valuable carrier for the controlled delivery of agrochemicals and genetic materials due to its proven biocompatibility, biodegradability, non-toxicity and adsorption capacity.

The closest to the discussed topic on the use of SD in agriculture should be recognized the work on the production and study of the insecticide Clothianidin in the form of its three forms based on a polymer NP obtained in a bead mill [20]. When studying photodegradation and sorption of Clothianidin by soil, it was found that these processes are rather transient and it is important to know for the future not only of the drug, but also of the carriers that were used to create the drug.

As is known, tebuconazole (TBC) is one of the widely used fungicides, and so were obtained its SD using of water-soluble polymers (AG, HES, PVP, pectin, etc.) to increase the solubility of TBC [55]. The obtained SDs were characterized by the data of X-ray and DSC analyzes and it 
was shown that joint mechanochemical treatment leads to partial disordering of the crystalline phase of TBC up to complete loss of crystallinity. The increasing of solubility of SD (12-14 times than the initial TBC) can explain high fungicidal activity against pathogens of root rot (Helminthosporium spp., Fusarium spp.) and other types of fungi (in particular, Penizillium spp.). At lower rates consumption of TBC (10-30 g/t) in comparison with the used branded drugs (eg, Raxil SC60 - the recommended rate is $60 \mathrm{~g} / \mathrm{t}$ ) confirmed that SDs were not only more cost effective but also less toxic. These results made it possible to recommend SD of the composition TBC / AG (1/5) as a promising fungicidal dressing agent [56]. To increase the adhesion properties of this SD, a surface-active component (powder of fruits of Sapindus trifoliates) was added to it, and after 3 hours of mechanical treatment at a module of 1:16, a beige free-flowing fine powder SD of the composition TBC / AG / surfactant (1/5/1), which easily formed a working solution for seed dressing and had increased solubility (up to 35 times) [57]. This protectant:

- had a positive effect on seed germination of soft spring wheat Novosibirskaya 29;

- effectively suppressed the growth of phytopathogenic microorganisms;

- had a positive impact on growth processes;

- showed a high level of healing effect on the root system of spring soft wheat grown on soil with a high density of spores of the phytopathogen Bipolaris sorokiniana;

- it was also effective in a field experiment to limit the damage to wheat plants by pathogens of common root rot.

To obtain the new SDs in the form of plant protection products against pests and diseases of grain crops, polysaccharides such as GA, its sodium salt $\left(\mathrm{Na}_{2} \mathrm{GA}\right)$, and EL were used to modify TBC [58]. To optimize the solubility parameter of SD based on TBC and polysaccharides, compositions in ratio of 1/5,1/10 and 1/20 were prepared. Optimally, the maximum solubility was possessed by the following compositions (data on the increase in solubility are given in parentheses): TBC / GA (1/5) (34 times); TBC / Na2GA (1/5) (2.9 times); TBC / EL (1/10) (15.2 times). The obtained SDs reduced the crystallinity of the original TBC (but it remains), the particles amorphize and, having irregular shapes, their sizes are 5-10 $\mathrm{mm}$. The obtained SDs had increased biological activity on spring barley with a 2-5-fold decrease in the consumption rate of TBA [59].

Using Chitosan as a polymer to obtain SD of TBC / chitosan (1/10) to improve the solubility of TBC, this approach was shown to be promising. Since the obtained SD, despite that it had only a 1.2-fold increased solubility, showed high biological efficacy against Puccinia recondita, Septoria nodorum and Blumeria graminis with a single processing of soft spring wheat, which led to an increase in grain yield by $0.55 \mathrm{t} /$ ha. It should also be noted that, in this SD the TBC consumption decreased by 5.5 times [60].

A review [61] concern the preparation of TBC and other fungicides (benomyl, prothioconazole, etc.) with the above and new polysaccharides (Kelp extraxt, Fucus vesiculosus extract, Saponins, etc.) by solid-phase mechanochemical treatment is given. Based on the results of these studies, it can be concluded that the proposed technology of mechanochemical modification of the substances of pesticide preparations is universal and allows it to be applied to biologically active substances and auxiliary components differing in physical and chemical properties. In this case, SDs of pesticide preparations are obtained with high efficiency while reducing the rate of use of the active substance $[62,63]$.

Among the various methods to protect potatoes from common diseases, the most economical and environmentally friendly is tuber dressing. Based on TBC, Thiram and Benzimidazole 
fungicides, protectants (in the form of SD ) have been developed for use on potatoes against various diseases. The solid-phase mechanochemical modification of these fungicides with the water-soluble polymers made it possible to obtain SDs that possessed high biological activity with a reduced dosage of active substances 10 and more times due to their influence on the properties of cell membranes. [64].The biological tests of these SDs indicated a decrease in the number of tubers of patients with dry rot 1.6-2.0 times in comparison with the control variant, and they were also more effective than the standard preparation (Colfugo Super, SC 60) 1.2-1.3 times. The proposed preparations significantly reduced the development of Rhizoctoniosis in the period of sprouting 5.8-7.3 times or the plants were completely healthy, and in the buddingflowering stage 2.7-5.5 times. The preparations provided a reliable yield increase, and also reduced the weight percentage of unsuitable tubers and significantly increased the yield of healthy tubers [65].

\section{Conclusion}

A brief review of works devoted to the development and application of SD in agriculture, in particular, for animal health and plant protection, suggests that the mechanochemical modification technology is promising for improving the properties of physiologically active substances used in various branches of agriculture.

The advantages of the method of mechanochemical modification of BAS the followings: - one-stage, because the process of obtaining SD takes place in one stage when loading the initial components into the drum of a ball mill;

-the ability to obtain SD not only from 2 components, but also more (no restrictions) for which it is impossible to select solvents with a common area of dissolution.

- versatility, because the method is acceptable for a wide range of biologically active substances used in medicine, veterinary medicine and plant protection;

-exclusion of their process of using organic solvents, which are explosive, flammable and lead to the formation of large amounts of waste;

- scalability of the process.

\section{Conflicts of Interest}

The author declares no conflict of interest.

\section{Acknowledgment}

Review based on investigations were carried out on the basis of Nesmeyanov Institute of Elementoorganic compounds RAS (budgetary organization) with the support the Ministry of Science and Higher Education of the Russian Federation .

Author would like to thank Colleagues from other Institutes of RF for opportunity to fulfill these investigations:

-Prof. Natalia G.Vlasenko, Prof. Anna A,Malyuga and Prof. Victor A. Marchenko and their teams from Center of Agrobiotechnology of SB RAS (Krasnoobsk and Barnaul); -Prof. Ivan A. Arkhipov and its Laboratory from All-Russian Scientific Research Institute of Fundamental and Applied Parasitology of Animals and Plants RAS (Moscow); -Prof. Alexander V. Dushkin and its Scientific Group from Institute of Solid State and Mechanochemisty of SB RAS (Novosibirsk).

\section{References}


1. Chiou W.L.; Riegelman S. Pharmaceutical applications of Solid dispersion systems. $J$ Pharm Sci. 1971, 60, 1281-1302. doi: 10.1002/jps.2600600902.

2. Kalia A.; Poddar M. Solid Dispersions: an Approach towards Enhancing Dissolution Rate: a Review. Int J Pharm Pharm Sci. 2011, 3, 9-19.

3. Dhirendra K.: Lewis S.; Udupa N.; Atin K. 2009. Solid dispersions: a Review. Pak. J. Pharm. Sci. 2009, 22, 234-246.

4. Yadav B.; Tanwar E.S. Applications of solid dispersions. J Chem Pharm Res. 2015, 7, 965-978.

5. Mankar S.D.; Rachh P.R. Solubility Enhancement of poor water soluble Drugs by Solid Dispersion: a Review. J Drug Delivery \& Therapeutics 2018, 8, 44-49.

6. Vasconcelos T.; Sarmento B.; Costa P. Solid dispersions as strategy to improve oral bioavailability of poor water soluble drugs. Drug Discovery today 2007, 12, 1068-1075.

7. Bobe K.R.; Subrahmanya C.R.; Suresh S.; Gaikwad D.T.; Patil M.D.; Khade T.S.; Gavitre B.B.; Kulkarni V.S.; Gaikwad U.T. Formulation and Evaluation of Solid Dispersion of Atorvatstatin with various carriers. Pharmacie Globale (IJCP) 2011, 02, 16.

8. Shende M.; Fiske P. Fabrication and optimization of novel glipizide sustained release matrices for solubility and dissolution enhancement by solid dispersion through hydrophillic carriers. J Drug Delivery and Therapeutics 2017, 7, 38-48. https://doi.org/10.22270/jddt.v7i6.1538

9. Nagasamy V.D.; Saraswathi S.; Priya P.M.; Khan N. I.; Kathirulla N.; Sruthi S. Dissolution enhancement of diacerein using water soluble carrier by solid dispersion technology. J Drug Delivery and Therapeutics 2017, 7, 33-41. https://doi.org/10.22270/jddt.v7i5.1503

10. Sareen S.; Mathew G.; Joseph L. Improvement in solubility of poor water-soluble drugs by solid dispersion, Int J Pharm Investigation 2012, 2, 12-17. doi: 10.4103/2230973X.96921

11. Kim K.T.; Lee J.Y.; Lee M.Y.; Song C.K.; Choi J.; Kim D. Solid Dispersions as a Drug Delivery System. J Pharm Investigation 2011, 41, 125-142.

12. Leuner C.; Dressman J. Improving drug solubility for oral delivery using solid dispersions. Eur J Pharm Biopharm 2000, 50 ,47-60.

13. Jadhav Y.L.; Parashar B.; Ostwal P.P.; Jain M.S. Solid Dispersion: Solubility Enhancement for Poorly Water Soluble Drug. Res J. Pharm. and Tech. 2012, 5, 190-197.

14. Dalvi P.B.; Gerange A.B.; Ingale P.R. Solid Dispersion: Strategy to Enhance Solubility. J Drug Delivery \& Therapeutics 2015, 5, 20-28.

15. Wagh V.T.; Wagh R.D. Solid Dispersion Techniques for Enhancement of Solubilization and Biovailability of poorly water soluble Drugs: a Review. IJPT April-2015, 6, 30273045.

16. Mankar S.D.; Rachh P.R. Solubility Enhancement of poor water soluble Drugs by Solid Dispersion: a Review. J Drug Delivery \& Therapeutics 2018; 8, 44-49.

17. Kashyap P.L.; Xiang X.; Heiden P. Chitosan nanoparticle based delivery systems for sustainable agriculture- a Review. Int J Biological Macromolecules 2015, 77, 36-51.

18. Kheiri A.; Moosawi Jorf S.A.; Malihipour A.; Saremi H.; Nikkhah M. Application of chitosan and chitosan nanoparticles for the control of Fusarium. Int J Biological Macromolecules 2016, 93,1261-1272.

19. Chhipa H. Nanofertilizers and nanopesticides for agriculture. Environ Chem Lett 2017, $15,15-22$.

20. Kah M.; Walch H.; Hofmann T. Environmental fate of nanopesticides: durability, sorption and photodegradation of nanoformulated clothianidin. Environ. Sci.: Nano 2018, 5, 882-889. 
21. Castillo J.A.; Palomo-Canales J.; Garcia J.J.; Lastres J.L.; Bolas F.; Torrado J.J. Preparation and characterization of albendazole $\beta$-cyclodextrin complexes. Drug Dev Ind Pharm 1999, 25, 1241-1248.

22. Kalaiselvan R.; Mohanta G.P.; Madhusudan S.; Manna P.K.; Manavalan R. Enhancement of bioavailability and anthelmintic efficacy of albendazole by solid dispersion and cyclodextrin complexation techniques. Pharmazie 2007, 62, 604-607.

23. Kalaiselvan R,; Mohanta G.P.; Manna P.K.; Manavalan R. Inhibition of albendazole crystallization in poly(vinylpyrrolidone) solid molecular dispersions. Pharmazie 2006, 61, 618-624.

24. Khalikov S.S.; Kutlymuratov A.P.; Kristallovich E.L.; Abdullaev N.D.; Khodzhaeva M.A.; Sadykov T.; Aripov K.N. Modification of the solubility of benzimidazole drugs on mechanical treatment with pectins. Chem Nat Compd 1995, 31, 460-464. https://link.springer.com/article/10.1007/BF01177411.

25. Lopatina N.S.; Dzhabarova V.I.; Lebedeva M.N. Pharmacokinetics of medamine and its solid polymer form (medapec) in experimental larval alveolar echinococcosis cotton rats. Medical Parasitology and parasitic diseases 2000, 3, 37-40.

26. Dzhabarova V.I.; Kovalenko F.P.; Lebedeva M.N. Experimental study of the suitability of Medapec as the drug of choice for treatment of echinococcosis. Medical Parasitology and parasitic diseases 2004, 4, 40-44.

27. Khalikov S.S.; Lokshin B.V.; Ilyin M.M.; Varlamova A.I.; Musaev M.B.; Arhipov A.I. Methods for obtaining solid dispersions of drugs and their properties. Russian Chemical Bulletin, International Edition 2019, 68, 1924-1932. https://doi.org/10.1007/s11172-0192648-3.

28. Khalikov S.S.; Zhuravleva G.P.; Larin P.P.; Kogan L.P.; Aripov K.N. Study of the properties of microcrystalline cellulose and its polycomplex with a benzimidazole drug after mechanical activation. Chem Nat Compd 1995, 31, 251-253. https://link.springer.com/article/10.1007/BF01170219.

29. Burkhanova N.D.; Yugai S.M.; Khalikov S.S.; Turganov M.M.; Muratova S.A.; Nikonovich G.V.; Aripov K.N. Interaction of drugs with microcrystalline cellulose at the molecular and supermolecular levels. Chem Nat Compd 1997, 33, 340-346. https://link.springer.com/article/10.1007/BF02234892.

30. Khalikov S.S.; Pominova T.Y.; Avgeeva A.V.; Kuliev Z.A.; Aripov K.N. Mechanicochemical interaction of plant proanthocyanidins with drugs. Chem Nat Compd 1995, 31, 184-186. https://link.springer.com/article/10.1007/BF01170201.

31. Campbell W.C. Benzimidazoles: veterinary uses. Parasitology Today 1990, 6, 130-133. https://doi.org/10.1016/0169-4758(90)90231-R.

32. Khalikov S.S.; Chistyachenko Y.S.; Dushkin A.V.; Meteleva E.S.; Polyakov N.E.; Arkhipov I.A.; Varlamova A.I.; Glamazdin I.I.; Danilevskaya N.V. Creation of highefficiency anthelmintic preparations based on intermolecular complexes of active substances with water-soluble polymers, including polysaccharides. Chemistry for sustainable development 2015, 23, 567-577. doi: 10.15372 / KhUR20150510.

33. Chistyachenko Y.S.; Meteleva E.S.; Pakharukova M.Y.; Katokhin A.V.; Khvostov M.V.; Varlamova A.I.; Glamazdin I.I.; Khalikov S.S.; Polyakov N.E.; Arkhipov I.A.; Tolstikova T.G.; Mordvinov V.A.; Dushkin A.V.; Lyakhov N.Z. Physicochemical and pharmacological study of the newly synthesized complex of albendazole and polysaccharide arabinogalactan from larch wood. Current Drug Delivery 2015, 12, 477490. doi:10.2174/1567201812666150518094739.

34. Патент РФ № 2546535 (2015).

35. Ivan A. Arkhipov, Salavat S. Khalikov, Konstantin M. Sadov, Alexandr V. Dushkin, Elizaveta S. Meteleva,Anastasiya I. Varlamova,, Irina M. Odoevskaya, Natalia V. Danilevskaya. Influence of mechanochemical technology on anthelmintic efficacy of the 
supramolecular complex of fenbendazole with polyvinylpyrrolidone. Journal of advanced veterinary and animal research, 2019 March, 6 (1):133-41; doi:10.5455/javar.2019.f323.

36. Pat. RF 2558922 (2015).

37. Varlamova A.I.; Arkhipov I.A,; Khalikov S.S.; Arisov M.V.; Sadov K.M.; Dushkin A.V. Increasing the biological activity of benzimidazoles based on the supramolecular nanoscale delivery system with licorice extract against helminthiasis. IOP Conf. Ser.: Earth Environ. Sci. 2020, 548, 042012, 1-6. doi:10.1088/1755-1315/548/4/042012.

38. Musaev M.B.; Khalikov M.S.; Milenina M.V.; Dzhamalova A.Z.; Bersanova H.I.; Iriskhanov I.V. Commission and field testing of efficacy of the supramolecular complex of triclabendazole «Triclafascid» against cattle fascioliasis. Rus J Parasitology 2018, 12, 76-80. doi:10.31016/1998-8435-2018-12-1-76-80.

39. Medvedeva E.N.; Babkin V.A.; Ostroukhova L.A. Arabinogalactan of larch - properties and prospects of use: a Review. Chem Plant Raw materials 2003, 1, 27-37.

40. Pat RF 2640482 (2016).

41. Varlamova A.I.; Movsesyan S.O.; Arkhipov I.A.; Khalikov S.S.; Arisov M.V.; Kochetkov P.P.; Abramov V.E.; Ilyin M.M.; Lokshin B.V. Biological Activity and Pharmacokinetic Behavior of Fenbendazole Integrated into a Supramolecular Delivery System with Licorice Extract and Sodium Dioctyl Sulfosuccinate. Biology Bull. 2020, 47, 565-574. doi: 10.1134/S1062359020060138.

42. Pat RF 2709019 (2019).

43. Varlamova A.I.; Limova Y.V.; Sadov K.M.; Sadova A.K.; Belova E.E.; Radionov A.V.; Khalikov S.S.; Chistyachenko Y.S.; Dushkin A.V.; Skira V.N.; Arkhipov I.A. Efficacy of the supramolecular complex of Fenbendazole against nematodiasis in sheep. Rus $J$ Parasitology 2016, 35, 76-81. https://www.elibrary.ru/item.asp?id=25719212.

44. Varlamova A.I.; Arkhipov I.A.; Khalikov S.S.; Sadov K.M. Efficiency of fenbendazole on the basis of nanosized supramolecular delivery systems with polyvinylpyrrolidone and dioctyl-sulphosuccinate sodium in the cases of helminthosis. Rus J Parasitology 2019; 13, 56-63. doi: 10.31016/1998-8435-2019-13-1-56-63.

45. Arkhipov I.A.; Sadov K.M.; Limova Y.V.; Sadova A.K.; Varlamova A.I.; Khalikov S.S.; Dushkin A.V.; Chistyachenko Y.S. The Efficacy of the supramolecular complexes of Niclosamide obtained by mechanochemical technology and targeted delivery against cestode infection of animals. Vet Parasitology 2017, 246, 25-29. https://doi.org/10.1016/j.vetpar.2017.08.019.

46. Pat RF 2588368 (2016).

47. Limova Y.V,; Sadov K.M,; Kanatbaev S.G.; Arkhipov I.A. Anthelmintic efficacy of Phenasalum based on supramolecular Drug Delivery Systems at monieziasis in cattle. Rus J Parasitology 2016, 36, 223-227. https://www.elibrary.ru/item.asp?id=27339256.

48. Limova Y.V.; Sadov K.M.; Korogodina E.V.; Arkhipov I.A.; Khalikov S. S. Anthelmintic Efficiency of new Phenasal formulations based on supramolecular, nanoscale Drug Delivery Systems for anoplocephalidosis in horses. Rus J Parasitology 2017, 40, 188-191. https://www.elibrary.ru/item.asp?id=30108471.

49. Arkhipov I.; Khalikov S.; Dushkin S.; Sadov K.; Meteleva E.; Arisov M.; Varlamova A. Anthelmintic Efficacy of Supramolecular Complex of Praziquantel Obtained by Mechanochemical Technology. Iran J Parasitol Jul-Sep 2020, 15, 364-373. doi: https://doi.org/10.18502/ijpa.v15i3.4201.

50. Lagereva E.V.; Abramov V.E.; Musaev M.B.; Khalikov S.S. Efficacy of supramolecular complex based on Albendazole and Triclabendazole against fasciolosis and gastrointestinal nematodosis of sheep. Rus J Parasitology 2019, 13, 82-88. doi: 10.31016/1998-8435-2019-13-2-82-88. 
51. Marchenko V.A.; Khalikov S.S. Supramolecular complexes of drugs for parasitic sheep infestations. IOP Conf. Ser.: Earth Environ. Sci. 2020, 548 082006, 1-12. doi:10.1088/1755-1315/548/8/082006.

52. Marchenko V.A.; Khalikov S.S.; Vasilenko Y.A.; Ilyin M.M.; Kravchenko I.A. Innovative anthelmintic based on mechanochemical technology and their efficacy against parasitic infection of sheeps. $J A d v$ Vet Animal Res. 2020 November, 7, 8718-8725; doi: 10.5455/javar.2020.g473.

53. Pat RF 2699799 (2019).

54. Van S.N.; Minh H.D.; Anh D.N. Study on Chitosan nanoparticles on biophysical characteristics and growth of Robusta Coffee in greenhouse. Biocatalysis and Agricultural Biotechnology 2013, 2, 289-294.

55. Khalikov S.S.; Dushkin A.V.; Davletov R.D.; Evseenko V.I.Creation of innovative fungicides based on Tebuconazole with the involvement of mechanochemical processes. Fundamental Res. 2013, 12, 2695-2700. https://elibrary.ru/item.asp?id=20960948.

56. Pat RF 2469536 (2012).

57. Khalikov S.S.; Teplyakova O.I.; Vlasenko N.G.; Khalikov M.S.; Evseenko V.I.; Dushkin A.V. Application of Arabinogalactan for improvement of technological and biological properties of grain culture protectants. Chemistry for sustainable development 2015, 23 , 591-599. https://elibrary.ru/item.asp?id=24860843.

58. Meteleva E.S.; Evseenko V.I.; Teplyakova O.I.; Khalikov S.S.; Polyakov N.E.; Apanasenko E.I.; Dushkin A.V.; Vlasenko N.G. Nanopesticides based on supramolecular Tebuconazole complexes for the treatment of cereal seeds. Chemistry for sustainable development 2018, 26, 279-294. doi: 10.15372/KhUR20180304.

59. Pat RF №2619249 (2017).

60. Meteleva E.S.; Evseenko V.I.; Teplyakova O.I.; Kulagin O.V.; Selyutina O.Y.; Polyakov N.E.; Dushkin A.V.; Vlasenko N.G. Innovative means of protecting spring wheat based on Chitohan obtained by Mechanochemistry methods. Chemistry for sustainable development 2020, 28, 57-65. doi: 10.15372/KhUR2020203.

61. Vlasenko N.G.; Khalikov S.S.; Burlakova S.V.FlexibileTechhology of Protectants for Grain Seeds.IOP Conf. Ser.: Earth Environ. Sci.2020, $548082003,1-10$. doi:10.1088/1755-1315/548/8/082003.

62. Pat RF 2592616 (2016).

63. Pat RF 26446625 (2018).

64. Khalikov S.S.; Malyuga A.A.;Chulikova N.S. Complex preparations for the protection potato on the basis ofTebuconazole. JAgr Sci.\& Technology A2019, 9, 338-343.doi: 10.17265/2161-6256/2019.06.002.

65. Pat RF 2602447 (2016). 